\title{
Exploring the $\mathrm{pH}$ dependence of viologen reduction by $\alpha$-carbon radicals derived from Hcy and Cys ${ }^{\dagger}$
}

\author{
Dong Wang ${ }^{a}$, William E. Crowe ${ }^{a}$, Robert M. Strongin ${ }^{b}$, and Martha Sibrian-Vazquez ${ }^{b}$ \\ William E. Crowe: wcrowe1@lsu.edu \\ aDepartment of Chemistry, Louisiana State University, Baton Rouge, LA 70803, USA. Fax: +1225 \\ 578 3458; Tel: +1 2255782060

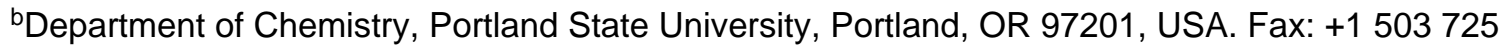 \\ 9525; Tel: +15037259724
}

\section{Abstract}

The colorimetric reaction of homocysteine $(\mathrm{HCy})$ with a series of viologen salts suggests a linear correlation between the mid-point reduction potential of Hcy-derived $\alpha$-carbon radicals and $\mathrm{pH}$.

\begin{abstract}
There has been great interest in the development of selective methods for the detection of homocysteine (Hcy) as it is a biomarker for a wide range of diseases. ${ }^{1}$ Interference from structurally related biological thiols such as Cys and GSH, typically present in much higher concentration, hinders selective detection methods. Unlike Hcy, the relatively more common biological thiols, such as GSH, are typically associated with beneficial antioxidant activity. It is thus also important to understand the differences between the fundamental chemistry of Hcy and other biothiols.
\end{abstract}

Oxidizing thiyl radicals formed from biological thiols interconvert with reducing, $\alpha$-amino carbon-centered radicals under physiological, aerobic conditions (eqn (1)). Strongin et al. recently reported a colorometric detection method based on the selective reduction of colorless methyl viologen $\left(\mathrm{MV}^{2+}\right)$ to its blue radical cation $\left(\mathrm{MV}^{+\bullet}\right.$ by $\mathrm{Hcy}$ at neutral $\mathrm{pH} .^{2}$ The selectivity of this detection method for Hcy was proposed to arise from an intramolecular hydrogen atom abstraction converting the oxidizing Hcy thiyl radical to the reducing Hcy $\alpha$-amino carboncentered radical through a kinetically favorable, five-membered ring transition state (eqn (2)). ${ }^{3}$ Earlier work by Zhao et al. had shown that at $\mathrm{pH} 10.5$ colorimetric detection of GSH, Cys, and Hcy was observed with no discernible selectivity. ${ }^{3,4}$ Interconversion of thiyl radicals with reducing disulfide radical anions (eqn (3)) becomes more prominent with increasing $\mathrm{pH}$, and it is possible that at $\mathrm{pH} 10.5$ nonselective $\mathrm{MV}^{2+}$ reduction results from the equally facile formation of disulfide radical anions from all three biological thiols.

\footnotetext{
${ }^{\dagger}$ Electronic supplementary information (ESI) available: Experimental details and spectroscopic data of prepared viologens.

(C) The Royal Society of Chemistry 2009

Correspondence to: William E. Crowe, wcrowe1@lsu.edu.
} 


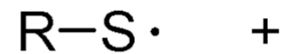

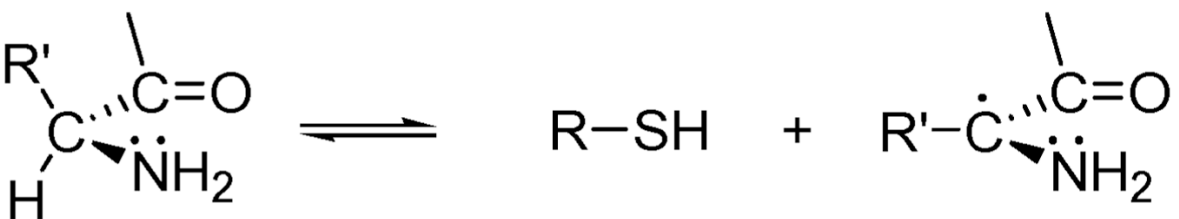

(1)

$$
\mathrm{R}-\mathrm{S}^{\bullet}+\mathrm{R}-\mathrm{S}^{-} \rightleftharpoons[\mathrm{R}-\mathrm{S}-\mathrm{S}-\mathrm{R}]^{\bullet-}
$$

Conducting the viologen-mediated colorimetric assay at neutral $\mathrm{pH}$ has the advantage of minimizing interference from nonselective $\mathrm{MV}^{2+}$ reduction by disulfide radical anions. However, captodative stabilization of $\alpha$-amino carbon-centered radicals requires lone pair donation from nitrogen, and at neutral $\mathrm{pH}$ only a small fraction of the amino groups is not protonated. This begs the question whether the reducing species producing the colorimetric response in the $\mathrm{MV}^{2+}$ assay could really be an $\alpha$-carbon radical. To address this question we propose herein a thermodynamic model for the $\mathrm{pH}$ dependence of the effective reduction potential of Hcy derived $\alpha$-carbon radicals and, using viologen indicators of varying reduction potentials, demonstrate that colorimetric changes occur at experimental $\mathrm{pH}$ values consistent with this model.

We also report the first examples, to our knowledge, of viologen reduction mediated by $\alpha$ amino carbon-centered radicals occurring at acidic $\mathrm{pH}$.

The ability of the carbon radicals to reduce a given substrate e.g., methyl viologen) has $\mathrm{pH}$ dependence which is determined by Scheme 1 .

The mid-point potential $E_{\mathrm{m}}\left(\mathrm{RC}^{+} / \mathrm{RC}^{*}\right)$ at a given $\mathrm{pH}$ determines whether the $\alpha$-carbon radical will be able to reduce a particular substrate. The following relationship between $E_{\mathrm{m}}\left(\mathrm{RC}^{+} /\right.$ $\left.\mathrm{RC}^{*}\right)$ and $\left[\mathrm{H}^{+}\right]$was derived from the Nernst equation: ${ }^{5}$

$$
\begin{aligned}
E_{\mathrm{m}}\left(\mathrm{RC}^{+} / \mathrm{RC}^{\bullet}\right)= & E^{\circ}\left(\mathrm{RC}^{+} / \mathrm{RC}^{\bullet}\right) \\
& +\frac{R T \ln 10}{F} \log \left[1+\frac{\mathrm{H}^{+}}{K_{\mathrm{obs}}}\right]
\end{aligned}
$$

where $E^{\circ}\left(\mathrm{RC}^{+} / \mathrm{RC}^{*}\right)$ is the standard potential, which is also the minimum value possible for $E_{\mathrm{m}}\left(\mathrm{RC}^{+} / \mathrm{RC}^{*}\right)$, and the pseudo-equilibrium constant, $K_{\mathrm{obs}}$, is given by:

$$
K_{\text {obs }}=\frac{K_{1} K_{2} K_{3}}{K_{1} K_{2}+K_{3}}
$$

When $\left[\mathrm{H}^{+}\right] \gg K_{\mathrm{obs}}($ low $\mathrm{pH}), E_{\mathrm{m}}$ varies linearly with $\mathrm{pH}$ :

Chem Commun (Camb). Author manuscript; available in PMC 2010 March 11. 


$$
\begin{aligned}
E_{\mathrm{m}}\left(\mathrm{RC}^{+} / \mathrm{RC}^{\bullet}\right) \approx & E^{\circ}\left(\mathrm{RC}^{+} / \mathrm{RC}^{\bullet}\right) \\
& +\frac{R T \ln 10}{F}\left[\log \left[\mathrm{H}^{+}\right]-\log K_{\mathrm{obs}}\right]
\end{aligned}
$$

At $298 \mathrm{~K}, R T \ln 10 / F=59.2 \mathrm{mV}$. Since $\mathrm{pH}=-\log \left[\mathrm{H}^{+}\right]$and we can define $\mathrm{p} K_{\mathrm{obs}}=-\log K_{\mathrm{obs}}$, the above equation can be re-written as:

$$
E_{\mathrm{m}}\left(\mathrm{RC}^{+} / \mathrm{RC}^{\bullet}\right)=E^{\circ}\left(\mathrm{RC}^{+} / \mathrm{RC}^{\bullet}\right)+59.2\left[\mathrm{p} K_{\mathrm{obs}}-\mathrm{pH}\right]
$$

When $\left[\mathrm{H}^{+}\right] \ll K_{\mathrm{obs}}$ (high $\mathrm{pH}$ ), the $\mathrm{pH}$-dependent part of the function goes to zero and $E_{\mathrm{m}}$ becomes constant, which is also the minimum value of $E_{\mathrm{m}}$.

$$
E_{\mathrm{m}}\left(\mathrm{RC}^{+} / \mathrm{RC}^{\bullet}\right)=E^{\circ}\left(\mathrm{RC}^{+} / \mathrm{RC}^{\bullet}\right)
$$

To test this model the effect of $\mathrm{pH}$ on the aminothiol-mediated reduction of a series of viologen indicators was determined. This was accomplished by gently refluxing a buffered, ${ }^{6}$ aqueous solution of the aminothiol (Hcy or Cys, $17 \mathrm{mM}$ ) and viologen (4.0 mM). Typically, color formation was observed (e.g., colorless to blue for $\mathrm{MV}^{2+}$ ) above a certain $\mathrm{pH}$. As the $\mathrm{pH}$ was increased, faster onset of color formation and deeper color change were observed as well as longer persistence of color after the sample was removed from heating. For several viologens there was a $\mathrm{pH}$ range where color formation is observed for Hcy but not Cys (selective Hcy detection). Hcy should have a stronger reduction potential because of the particularly favorable formation of $\alpha$-carbon radicals.

As solution $\mathrm{pH}$ decreases, we predict that $E_{\mathrm{m}}\left(\mathrm{RC}^{+} / \mathrm{RC}^{*}\right)$ should increase until $E_{\mathrm{m}}\left(\mathrm{RC}^{+} / \mathrm{RC}^{*}\right)>$ $E^{0}$ (viologen) at which point no color formation should be observed. Upon lowering the $\mathrm{pH}$ we observed slower onset of color formation and less intense color change as well as shorter persistence of the color after the sample was removed from heating. For six of the eight viologens $7^{-}$- examined we were able to obtain a $\mathrm{pH}$ endpoint (minimum $\mathrm{pH}$ where color formation was observable) below which no color formation occurred. As predicted, lower $\mathrm{pH}$ endpoints were observed for viologens possessing higher (i.e., less negative) reduction potentials ( $E^{0}$ values). No $\mathrm{pH}$ endpoint was observed (color formation for all $\mathrm{pH}$ values $\geq 0$ ) for the two most easily reduced viologens. These $\mathrm{pH}$ endpoint results are summarized in Table 1 . We propose that $E_{\mathrm{m}}\left(\mathrm{RC}^{+} / \mathrm{RC}^{*}\right) \approx E^{0}$ (viologens) for the $\mathrm{pH}$ endpoints obtained in entries 48 of this table. As can be seen from Table 1, entry 3 through entry 8 , viologens can be used to detect Hcy and Cys selectively during lower $\mathrm{pH}$. For example, benzylic viologen (entry 5) can be used to detect Hcy selectively between $\mathrm{pH} 3.6$ and $\mathrm{pH} 4.8$ since there is no color change for Cys.

Interestingly, phenyl viologen (entry 4) is found to be an excellent reagent to selectively detect Hcy and Cys. It can selectively detect Hcy and Cys not only in acidic conditions, but also in basic conditions. From $\mathrm{pH} 9$ to $\mathrm{pH} 12$, Hcy shows a green color at first (and finally turned blue) whereas Cys shows blue. Especially at pH 11, Cys turned blue within 5 min of gentle refluxing, whereas Hcy turned green after 10 min of gentle refluxing.

It is worth noting that most of the viologens (from entry 4 to entry 8 ) we tested showed a linear correlation between $\mathrm{pH}$ endpoint and $E^{0}$ (standard reduction potential of $\alpha$-carbon radicals). This linear relation exactly matches what we expected from eqn (6). Using the experimental data, we are able to get a line between $\mathrm{pH}_{\min }$ and $E^{0}$ (Fig. 1). 
We are currently unable to account for the discrepancy between the experimental endpoint and $\mathrm{pH}$ (calc.) for entry 3. Noting that the diacid analog of this viologen has a reduction potential of $-410 \mathrm{mV}$, it is tempting to attribute the higher $\mathrm{pH}$ endpoint to hydrolysis of the ester moiety. However, various control experiments have revealed that ester hydrolysis is minimal $(<5 \%)$ under the conditions of the viologen reduction experiment.

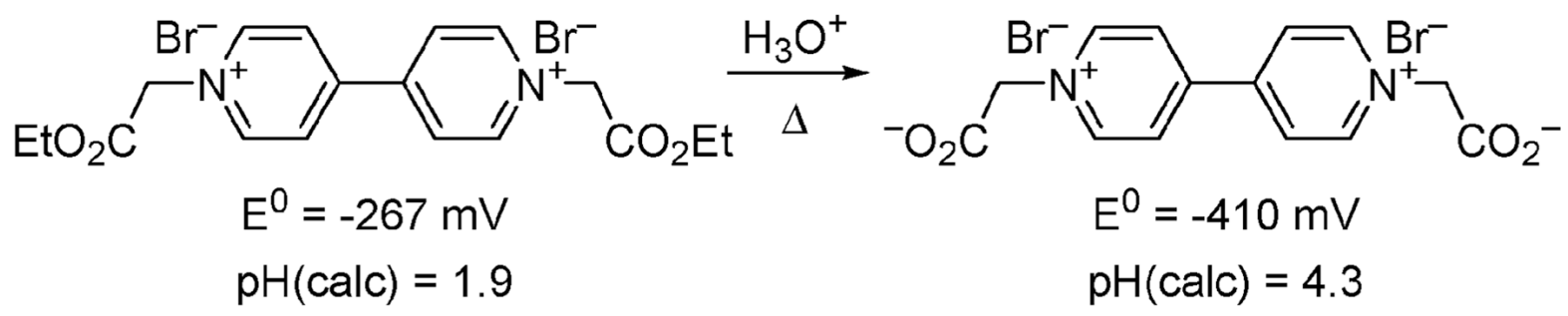

The absence of a pH endpoint for entries 1 and 2 is consistent with $\mathrm{pH}$ (calc.) $\leq 0$ for these two entries.

It seems that there are two color change ranges for Cys and alkyl viologens. Both of the two alkyl viologens, methyl and heptyl viologens (entry 8 and entry 7), showed two color change ranges when mixed with Cys (Table 1). The reason is unclear.

We also prepared dimethoxy viologen $\left(E^{0}=-651 \mathrm{mV}, \mathrm{pH}(\mathrm{calc})=8.4.\right)$ and found that no color formation occurred in the $\mathrm{pH}$ range 8-11. A tempting interpretation of this data is that the reduction potential of dimethoxy viologen is more negative than $E^{0}\left(\mathrm{RC}^{+} / \mathrm{RC}^{*}\right)$, and therefore there is no $\mathrm{pH}$ at which the mid-point potential $E_{\mathrm{m}}\left(\mathrm{RC}^{+} / \mathrm{RC}^{*}\right)$ is negative enough for dimethoxy viologen reduction to occur. This interpretation is represented graphically in Fig. 2.

This interpretation would allow us to bracket the standard potential of the homocysteinederived $\alpha$-carbon radical as: $-651 \mathrm{mV}<E^{0}\left(\mathrm{RC}^{+} / \mathrm{RC}^{*}\right)<-446 \mathrm{mV}$. While the upper value of this bracketing is certainly valid ( $-446 \mathrm{mV}$ for $\mathrm{MV}^{2+}$ falls on the linear part of the $E_{\mathrm{m}}\left(\mathrm{RC}^{+} /\right.$ $\left.\mathrm{RC}^{*}\right) v s . \mathrm{pH}$ curve), the lower value is uncertain. At $\mathrm{pH}=11$ there should be color formation associated with formation of the disulfide radical anion ([HcyS-SHcy $]^{\circ-}, E^{0} \approx-1700 \mathrm{mV}$ for $[\mathrm{CysS}-\mathrm{SCys}]^{\bullet-}$ ).

Lack of color formation at $\mathrm{pH}=11$ probably suggests that dimethoxy viologen is not stable at this $\mathrm{pH}$. Indeed, gently refluxing a solution of dimethoxy viologen at $\mathrm{pH} 11$ leads to complete conversion of the viologen to a mixture of decomposition products from which 4,4'-bipyridine can be isolated in $80-85 \%$ yield.

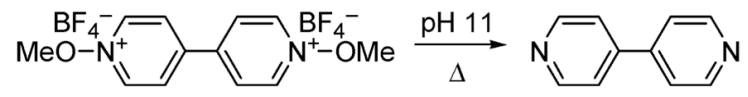

Net demethoxylation of dimethoxy viologen might occur by a $\beta$-elimination pathway where a pyridine leaving group is ejected and the methoxyl group is oxidized to formaldehyde. ${ }^{10} \mathrm{An}$ interesting possibility to explore is the preparation of a stable analog of dimethoxy viologen lacking this $\beta$-elimination decomposition pathway.

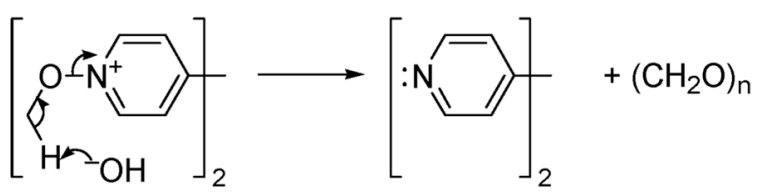


In summary, $\alpha$-aminoalkyl radicals can be generated under acidic conditions. The reduction potential of $\alpha$-carbon radicals was found to be $\mathrm{pH}$ dependent, and it shows a linear correlation between the reduction potential and $\mathrm{pH}$ for Hcy. The $\mathrm{pH}$ profiles of Cys and Hcy have been established for six viologens. Most of the viologens can be used to selectively detect Hcy and Cys under acidic conditons. The determination of standard reduction potentials of $\alpha$-carbon radicals is currently underway in our lab.

\section{Supplementary Material}

Refer to Web version on PubMed Central for supplementary material.

\section{Acknowledgments}

Support from the National Institutes of Health (R01 EB002044) is gratefully acknowledged.

\section{Notes and references}

1. (a) Nekrassova O, Lawrence NS, Compton RG. Talanta 2003;60:1085. [PubMed: 18969134] (b) Refsum H, Smith AD, Ueland PM, Nexo E, Clarke R, McPartlin J, Johnston C, Engbaek F, Schneede J, McPartlin C, Scott JM. Clin. Chem 2004;50:3. [PubMed: 14709635] (c) De Bree A, Verschuren WMM, Kromhout D, Kluijtmans LAJ, Blom HJ. Pharmacol. Rev 2002;54:599. [PubMed: 12429870]

2. (a) Wang WH, Rusin O, Xu XY, Kim KK, Escobedo JO, Fakayode SO, Fletcher KA, Lowry M, Schowalter CM, Lawrence CM, Fronczek FR, Warner IM, Strongin RM. J. Am. Chem. Soc 2005;127:15949. [PubMed: 16277539] (b) Wang WH, Escobedo JO, Lawrence CM, Strongin RM. J. Am. Chem. Soc 2004;126:3400. [PubMed: 15025448]

3. Zhao R, Lind J, Merenyi G, Eriksen TE. J. Am. Chem. Soc 1994;116:12010.

4. Zhao R, Lind J, Merenyi G, Eriksen TE. J. Chem. Soc., Perkin Trans 1997;2:569.

5. See, for example: Wardman P. J. Phys. Chem. Ref. Data 1989;18:1637.

6. Components of buffer solutions were as follows: $\mathrm{pH}$ 0.0-2.2: $\mathrm{HCl}+\mathrm{KCl} ; \mathrm{pH}$ 2.3-6.9: citric acid + $\mathrm{Na}_{2} \mathrm{HPO}_{4}$, pH 7.0-9.0: Tris + HCl; $\mathrm{pH}$ 10.0-11.0: $\mathrm{NaHCO}_{3}+\mathrm{NaOH} ; \mathrm{pH} 12.0-13.0: \mathrm{NaOH}+\mathrm{KCl}$.

7. While viologens in entries $1,4,5,7$ and 8 are commercially available, others were prepared by nucleophilic alkylation of 4,4'-bipyridine as described in the literature. ${ }^{8}$ Dimethoxy viologen was prepared by alkylation of $N$-oxide according to a known process 9 .

8. Bruinink J, Kregting CGA, Ponjee JJ. J. Electrochem. Soc 1977;124:1854.

9. Lorance ED, Kramer WH, Gould IR. J. Am. Chem. Soc 2002;124:15225. [PubMed: 12487598]

10. Feely W, Lehn WL, Boekelheide V. J. Org. Chem 1957;22:1135. 


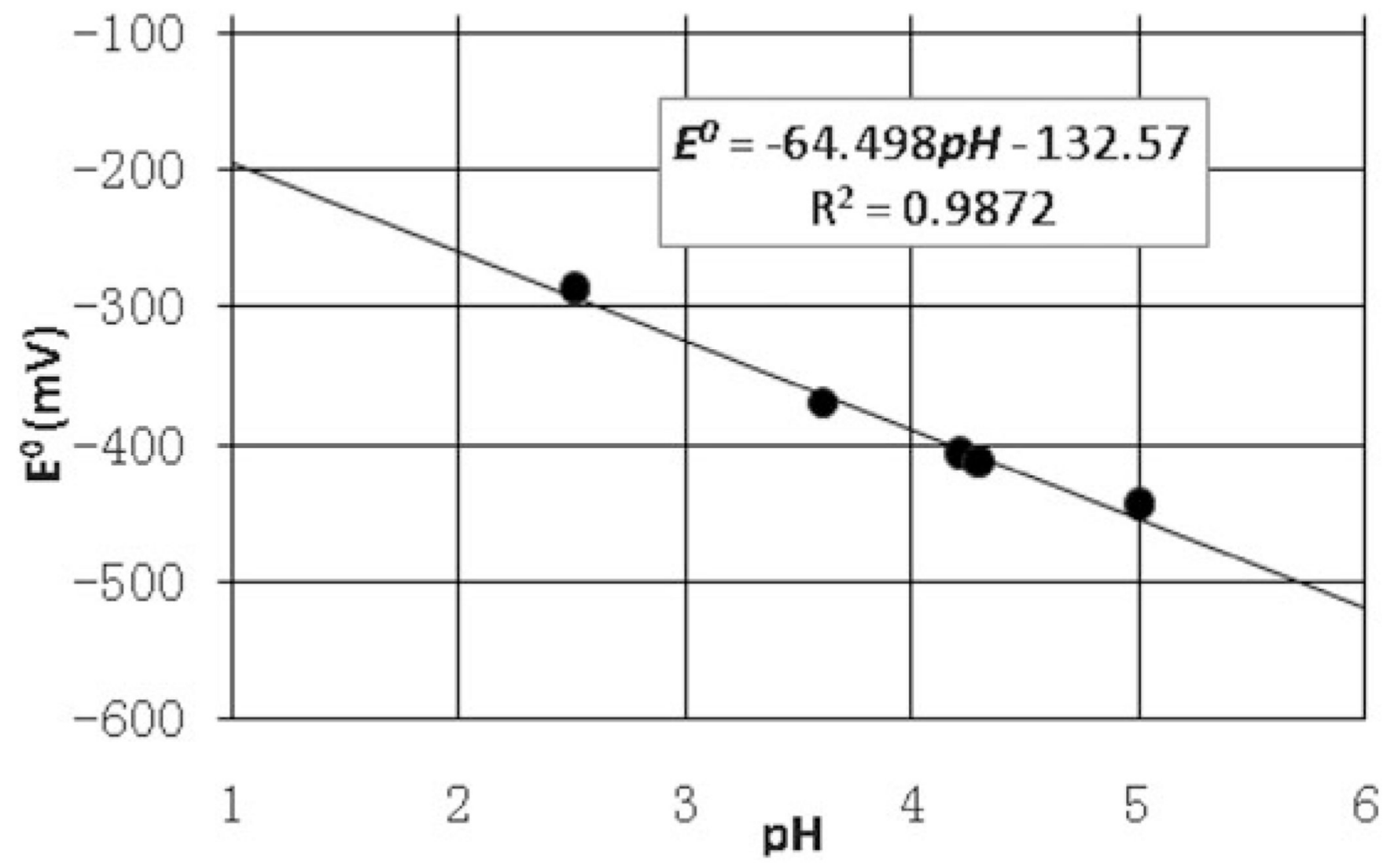

Fig. 1.

Reduction potential vs. pH plot. 


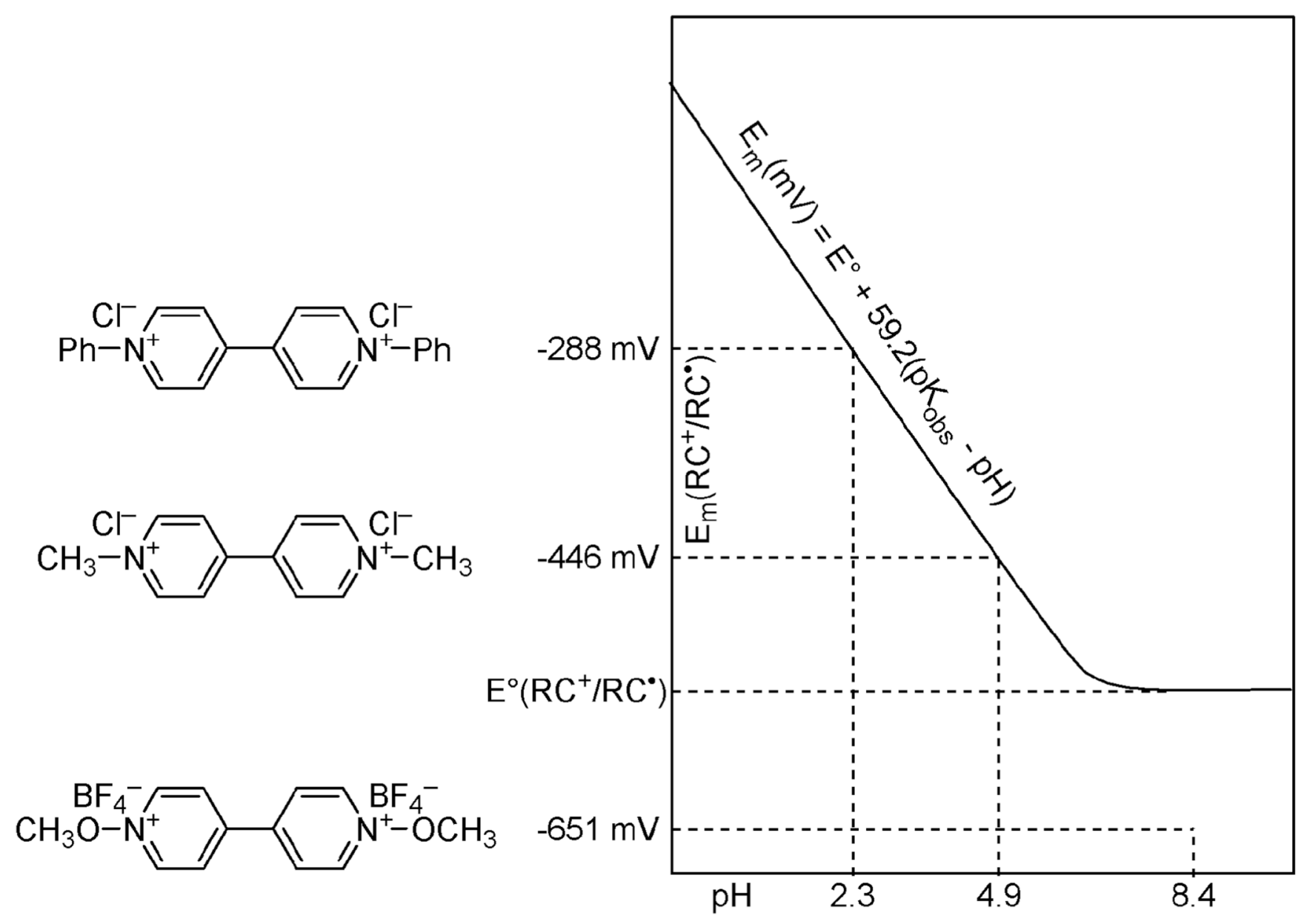

Fig. 2.

Reduction potential $v s$. whole $\mathrm{pH}$ range. 
<smiles>C#COC(=[PH2+])C([NH3+])CCS</smiles>

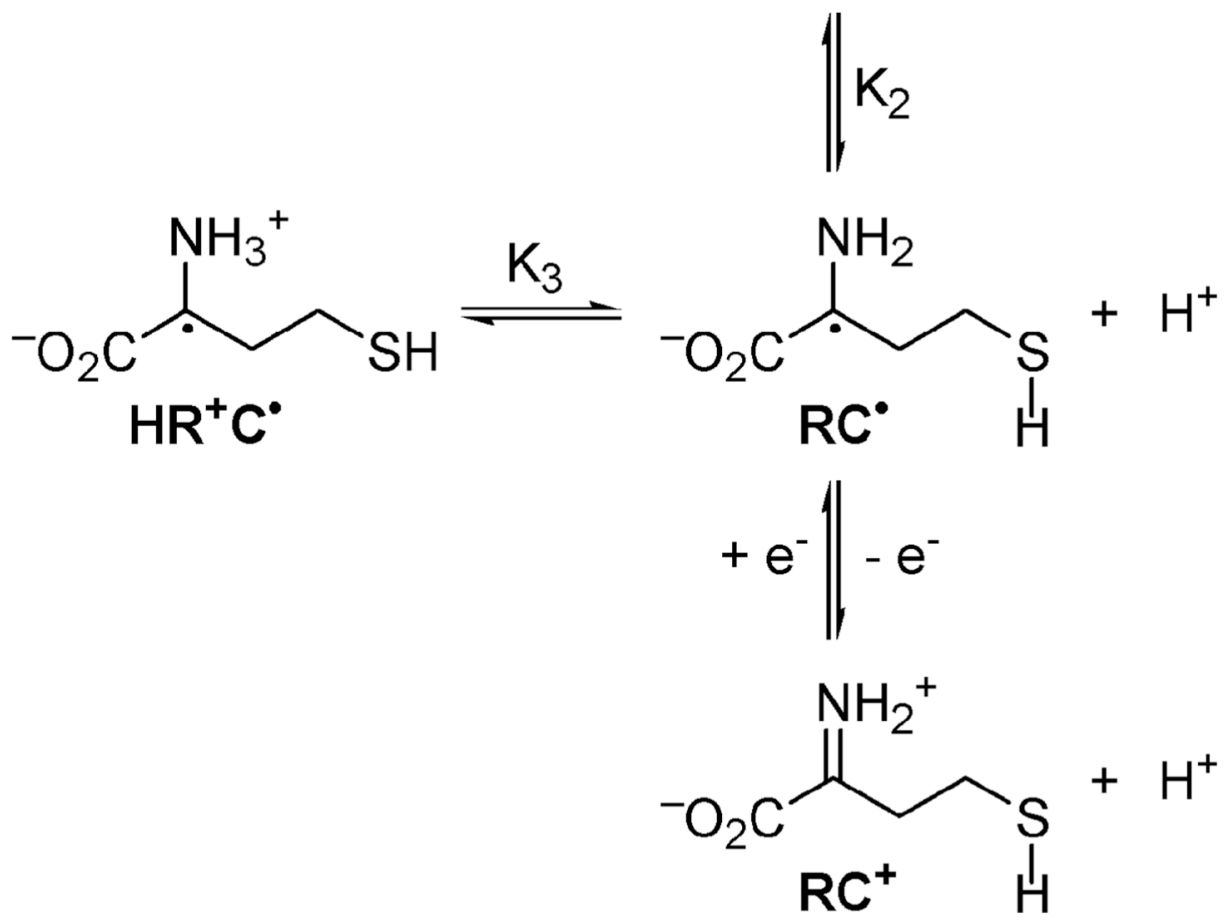

Scheme 1.

The equilibrium between thiyl radicals and carbon radicals. 


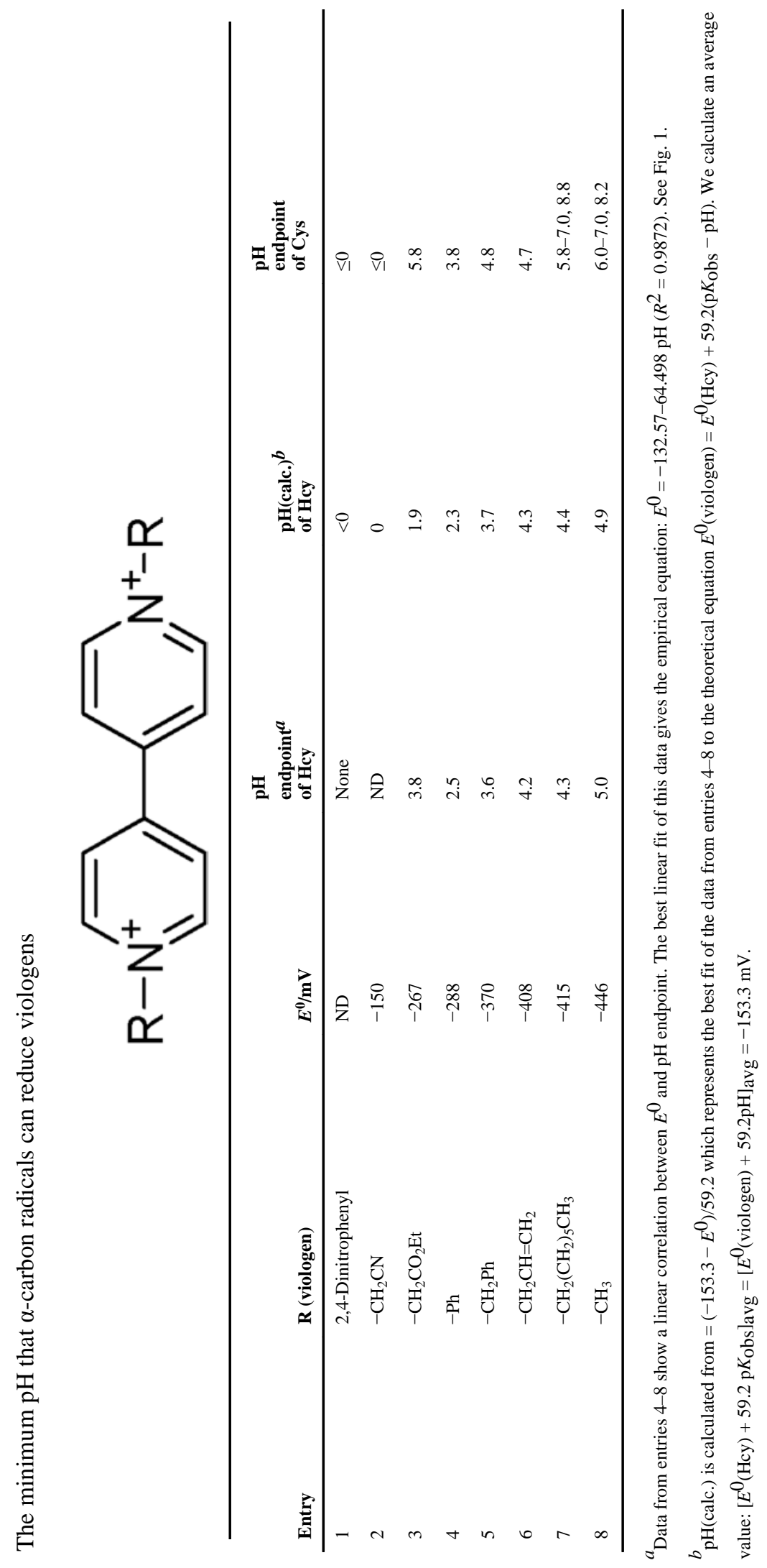

Chem Commun (Camb). Author manuscript; available in PMC 2010 March 11. 